\title{
Adsorption Equilibrium, Physicochemical Parameters and Colour Deactivation Effects of Activated Carbon for Dye for Waste Water Treatment
}

\author{
Alhassan, $M^{1^{*}}$ Muhammad Sani Aleiro $^{2} \quad$ Umar, A. $^{1}$ \\ 1. Department of Chemistry, Sokoto State University. Sokoto-Nigeria. \\ 2. Department of Chemistry, Kebbi State University of Science and Technology, Aleiro. Aleiro Kebbi State Nigeria.
}

\begin{tabular}{|c|c|}
\hline ARTICLE INFO & ABSTRACT \\
\hline Article history & \multirow{10}{*}{ 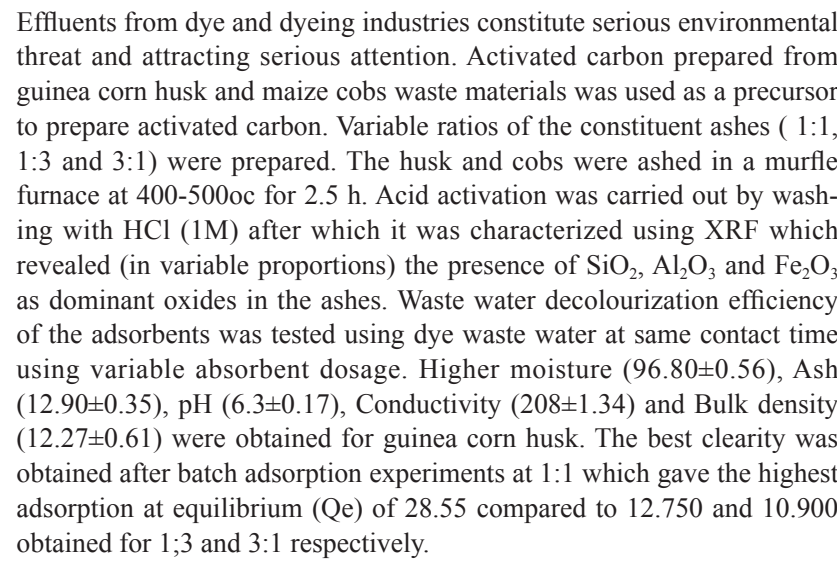 } \\
\hline Received: 1 December 2020 & \\
\hline Accepted: 8 January 2021 & \\
\hline Published Online: 30 March 2021 & \\
\hline & \\
\hline Keywords: & \\
\hline Adsorption equilibrium & \\
\hline & \\
\hline Activated carbon & \\
\hline Decolourization & \\
\hline
\end{tabular}

\section{Introduction}

Activated carbon has been utilized for different purposes by several authors as a highly porous, high surface-area adsorptive material with a largely amorphous structure. It is composed primarily of aromatic configurations of carbon atoms joined by random cross-linkages ${ }^{[1]}$. It is also a carbonaceous material with a large internal surface area and highly developed porous structure resulting from the processing of raw materials under high temperature reactions. It is about $87 \%$ to $97 \%$ carbon but also contains other elements depending on the processing method used and raw material it is derived from ${ }^{[2]}$.

*Corresponding Author:

Alhassan, $M$,

Department of Chemistry, Sokoto State University. Sokoto-Nigeria; E-mail:mansuralhassan@gmail.com
Activated carbon, activated charcoal or activated coal is a form of carbon that has been processed to make it extremely porous and thus to have a very large surface area available for adsorption of chemicals ${ }^{[3]}$, heavy metals ${ }^{[4]}$ toxic chemicals, separation of gases, recovery of solvents, removal of organic pollutants, petrochemicals etc. According to Bansal ${ }^{[5]}$, activated carbon is well known for its porosity and adsorption capacity thus it is used in environmental pollution control as well as in industry for various liquid and gas phase adsorptions.

Removal of dye in aqueous solutions is tedious to achieve due probably to their low concentration in aqueous solutions, inert synthetic properties as well as resis- 
tance among others ${ }^{[6-7]}$. Efforts put in place to remove dyes from aqueous solutions include ion exchange (Labanda et al.$^{[8]}$, Photocatalytic degradation (Lenzy et al. [9], coagulation (shi et al. ${ }^{[10]}$, physicochemical treatment (Akrabi et al. ${ }^{[11]}$; Pia et al. ${ }^{[12]}$, adsorption (Han et al. ${ }^{[13]}$; Shen et al. ${ }^{[14]}$; Lazim et al. ${ }^{[15]}$, Electrochemical (Tadda et al. ${ }^{[7]}$ and Mittal, ${ }^{[16]}$ among others.

The method of adsorption stands advantageous over the other ones, due to its effectiveness, ease of handling and dye removal, low operational cost in addition to being operated at low dye concentrations (Ngah et al. ${ }^{[17]}$; Mahmoodi et al ${ }^{[18]}$; Kiakhani et al. ${ }^{[19]}$.

Absorbents for decolourization of waste water effluents from chemical industries are increasingly getting attention. Synthesized active components of these adsorbents are readily available and effective for dye/waste treatments, but are expensive ${ }^{[20]}$.

On the other hand, naturally active plant materials (ranging from leaves, seeds, barks etc) have been tested for decolourization and most were reported to show excellent decolourization effect on waste water, but the rate of activity is reported to be slow and much of the adsorbent is required to treat less amount of water ${ }^{[20]}$.

Water continues to be an essential supporter of all forms of plant and animal life. In recent years, increasing awareness of organic and inorganic compounds, especially heavy metals that pollute the environment has prompted the purification of waste water before discharge into natural waters. A number of conventional methods of treatment technologies have been considered for treatment of waste water contaminated with organic /inorganic substances.

Accordingly, there is still need to develop adsorbents containing active synthetic compounds impregnated over natural support like carbonized charcoal from guinea corn husk and maize cobs which are cheaper (than their synthesized counterparts), more eco-friendlier, faster (than traditional) from readily available waste materials ${ }^{[19,20]}$.

\section{Dye Waste Water/ Activated Carbon Pre- cursors}

Waste water treatments especially of dyeing industry, consist of steps taken to utilize coloured waste water from dyeing/dye bath containing variety of dyes in different concentrations. This treatment process become necessary as there is need to decolourize (remove dye colour) prior to discharge of the waste water in order to minimize pollution; as per regustatutory environmental guidelines ${ }^{[12]}$.

Furthermore, sensitivity of the dye colour to intensifi- cation, especially in the presence of mordants (materials such as sodium sulphate, added to dye bath to control or promote action of a textile dye) used during dyeing process may add to the harmful nature of improperly handled dyes ${ }^{[15]}$.

A large amount of highly coloured waste water is discharged from textile and dyeing mills. Aziz and co-workers ${ }^{[20]}$, reported that biological treatment methods are usually cheap and easy to apply, but these processes are generally only efficient in biochemical oxygen demand (BOD)and suspended solids removal but largely ineffective for decolourization of the effluents.

This paper is aimed at the development of activated carbons from corn cobs and assessment of their efficiency for removing heavy metals from polluted minerals processing wastewater. A two-step activation process: carbonisation of samples of corn cobs followed by steam activation of the derived char at various durations of activation was used to obtain activated carbons of different surface areas and pore characteristics. The activated carbons were contacted with a solution containing appreciable levels of heavy metals to assess their heavy metal adsorption efficiencies ${ }^{[21]}$.

Many attempts were carried out in order to obtain a low cost activated carbon from agricultural waste ; almost any carbonaceous materials, with high carbon content and low inorganic components, may be used as precursor for the preparation of activated carbons such as coconut shell, corn cob, rice husk, millet husk maze husk and guinea corn husks etc ${ }^{[22]}$.

The activated carbon required for most industries (e.g., oil and gas, food, pharmaceutical, water and wastewater treatment, and gold recovery) is imported from countries such as China, Sri Lanka and the Netherlands at great expense. There is an opportunity to reduce the cost of these processes by producing activated carbon in Nigeria using domestically sourced raw material ${ }^{[23]}$.

Although high dependence on imported activated carbon is reportedly linked to the minimal research in the field, Odebunmi and Okeola ${ }^{[24]}$ and Itodo ${ }^{[25]}$ worked on comparative studies on the preparation, adsorption and evaluation of activated carbon from selected Agricultural wastes.

\section{Experimental}

\subsection{Methods}

(1) Sample Procurement/Treatment

Maize cobs and guinea corn husk and dye waste water (effluents) were obtained from a farm along dundaye area and dyeing spot in Sokoto respectively. Methylene blue 
dye was purchased from a chemical store in Sokoto State, Nigeria.

The methods of ${ }^{[25-28]}$ were adopted to remove surface impurities as well as sand, the cobs and husks were washed with clean water, filtered, sun-dried and oven-dried (overnight) at $105^{\circ} \mathrm{C}$ followed by grinding and sieving to particle sizes $<2 \mathrm{~mm}$ aperture sieve.

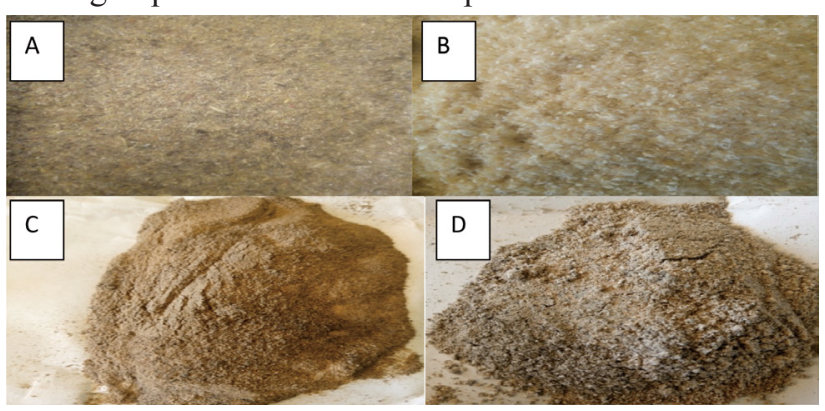

Figure 1. Guinea corn husk (A) and Maize cobs (B) prior to ashing and after ashing (C); and (D) respectively.

(2) Carbonization/Activation

Three (3) sets of pre-weighed ashing crucibles were labelled A, B and C. A contained $50 \mathrm{wt} \%$ each of maize cobs/guinea corn husk equally mixed in 1:1 ratio. B contains weight ratio of $1: 3$ having $25 \mathrm{wt} \%$ to $75 \mathrm{wt} \%$ of maize cobs/giunea corn husk while C contains $3 ; 1$ ( $75 \mathrm{wt} \%$ to $25 \mathrm{wt} \%$ ) weight ratio of maize cobs/guinea corn husk. The ashing was carried out $400-500^{\circ} \mathrm{c}$ for $2.5 \mathrm{~h}$ in a muffle furnace. Cooling and heating was repeatedly done until constant weights of carbonized samples were obtained as reported by ${ }^{[25,28]}$. The carbonized samples were washed using $10 \% \mathrm{HCl}$ to remove surface ash, followed by hot water washing and rinsing with distilled water to remove residual acid ${ }^{[29]}$.The solid residues were then air-dried, and oven- dried in the $105^{\circ} \mathrm{C}$ for $1 \mathrm{~h}^{[24]}$.

(3) Carbonization Yield

The yield on carbonization was calculated from the weight, before carbonization (Wbc) and after carbonization (Wac). The \% yield is calculated using the method reported by ${ }^{[31]}$.

Yield $(\%)=\mathrm{Wac} / \mathrm{Wbc} \times 100$

Wac $=$ weight after carbonization

$\mathrm{Wbc}=$ weight before carbonization

Methylene Blue Standards / Adsorption Test (w/v)

Methylene blue (100 g) was dissolved in distilled water in $1000 \mathrm{~cm}^{3}$ volumetric flask and made to the mark. This solution was used for serial dilutions to prepare 100, 80 , 60,40 and $20 \mathrm{~g} / \mathrm{dm}^{3}$ standards. Accurately weighed $0.2 \mathrm{~g}$ of each sorbent was placed in $20 \mathrm{ml}$ each of solution containing $10-50 \mathrm{mgl}^{-1}$ of MB and left to equilibrate for 8 hours ${ }^{[26]}$ After standing filtration was done and the absorbance of the filtrate (at $630 \mathrm{~nm}$ wavelength) was measured using UV-Vis spectrophotometer ${ }^{[26]}$.

\subsection{Characterization}

$\mathrm{X}$-ray diffraction was determined using according to the method of Alhassan et al. ${ }^{[32]}$ Its source of radiation is $\mathrm{Cu}-\mathrm{K} \alpha$ or $\mathrm{Al}-\mathrm{K} \alpha$ radiation. The spectra presents the intensity in counts per seconds (cps) against $2 \varnothing$ degrees diffraction angle where the most intense peak is us The XRD patterns were measured in the $2 \theta$ range of $20^{\circ}-120^{\circ}$ at a scan rate of 1 and $4 \% \mathrm{~min}$.

The FTIR analysis was carried out using using cary 630 model spectrophotometer. The scanning electron micsroscopy (SEM) spectra of the activated carbon fractions used in this work was recorded using a SEM Leica 440 instrument at accelerating voltage $10 \mathrm{kV}$ and magnification 500x.

\subsection{Results}

Table 1. Physicochemical Properties of Maize cobs/ Guinea Corn Husk Ash

\begin{tabular}{ccc}
\hline Parameters & Maize cobs & Guinea corn Husk \\
\hline Residual Moisture (\%) & $92.40 \pm 1.25$ & $96.80 \pm 0.56$ \\
Ash (\%) & $7.3 \pm 0.41$ & $12.90 \pm 0.35$ \\
pH & $5.1 \pm 0.45$ & $6.3 \pm 0.17$ \\
Conductivity (บs/cm) & $167 \pm 0.82$ & $208 \pm 1.34$ \\
Bulk density (\%) & $10.13 \pm 0.12$ & $12.27 \pm 0.61$ \\
\hline
\end{tabular}

Table 2. Adsorption Equilibrium (Qe) At $660 \mathrm{~nm}$

\begin{tabular}{cccc}
\hline Molar ratio(s) & Weight added (g) & Ce & Qe \\
\hline \multirow{2}{*}{$1: 1$} & 3 & 0.453 & -6.459 \\
& 2 & 0.487 & -11.084 \\
& 1 & 0.520 & 28.550 \\
$1: 3$ & 3 & 0.786 & -12.009 \\
& 2 & 0.801 & -18.934 \\
& 1 & 0.836 & 12.750 \\
$3: 1$ & 3 & 0.801 & -12.259 \\
& 2 & 0.827 & -19.634 \\
& 1 & 0.873 & 10.900 \\
\hline
\end{tabular}

Co was taken as the average absorbance for the methylene standard $(100,80,60,4020$ and $0 \mathrm{~g} / \mathrm{dm} 3$; variable weights were used in the equation $\mathrm{Qe}=(\mathrm{Co}-\mathrm{Ce}) \mathrm{v} / \mathrm{w}$. 
Table 3. XRF Analysis (Composition of Major elements/ Oxides) in Activated Charcoal Samples

\begin{tabular}{cccc}
\hline \multirow{2}{*}{$\begin{array}{c}\text { Major Oxide/Ele- } \\
\text { ment }\end{array}$} & $\begin{array}{c}\text { Composition (\%) } \\
\text { G(1:1) Maize/ } \\
\text { Guinea corn }\end{array}$ & $\begin{array}{c}\text { B (1:3) Maize/ } \\
\text { Guinea corn }\end{array}$ & $\begin{array}{c}\text { C (3:1) } \\
\text { Maize/ Guinea } \\
\text { corn }\end{array}$ \\
\hline $\mathrm{Fe}_{2} \mathrm{O}_{3}$ & 3.2851 & 3.26 & 2.1180 \\
$\mathrm{MgO}$ & 1.16 & 0.41 & 0.81 \\
$\mathrm{Al}_{2} \mathrm{O}_{3}$ & 3.356 & 2.600 & 3.166 \\
$\mathrm{SiO}_{2}$ & 83.951 & 87.53 & 75.417 \\
$\mathrm{Traces}$ & 8.2479 & 6.200 & 18.489 \\
\hline
\end{tabular}

Others $=$ trace amounts of about 20 oxides ranging from $\mathrm{ZrO}_{2}, \mathrm{Y}_{2} \mathrm{O}_{3}, \mathrm{SrO}, \mathrm{RbO}_{2}, \mathrm{Br}, \mathrm{As}_{2} \mathrm{O}_{3}, \mathrm{CeO}_{2}, \mathrm{La}_{2} \mathrm{O}_{3}$, etc

Table 4. Yield of Recovered Absorbent From the Ashes

\begin{tabular}{cccc}
\hline $\begin{array}{c}\text { Initial Adsorbent } \\
\text { Dose (g) }\end{array}$ & Sample & Mass recovered (g) & Yield (\%) \\
\hline \multirow{2}{*}{1} & A (1:1) & 0.09 & 9.79 \\
& B (1:3) & 0.0732 & 7.32 \\
& C (3:1) & 0.0667 & 6.67 \\
2 & A (1:1) & 0.213 & 10.65 \\
& B (1:3) & 0.195 & 9.75 \\
& C (3:1) & 0.108 & 5.40 \\
3 & A (1:1) & 0.4794 & 15.98 \\
& B (1:3) & 0.5031 & 16.77 \\
& C (3:1) & 0.4092 & 13.64 \\
\hline
\end{tabular}

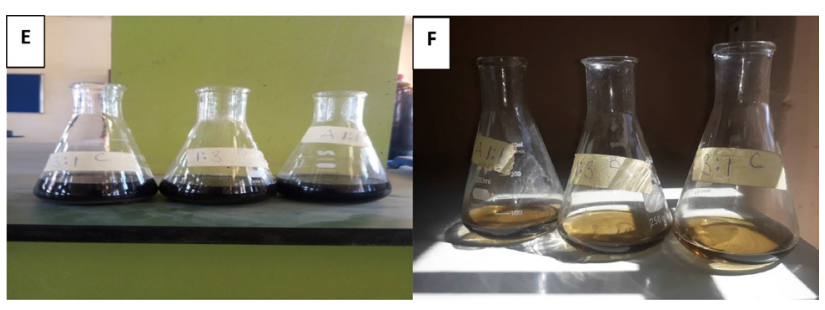

Figure 2. Dye waste water before (E) and after (F) adsorbent decolourization

\section{Discussion}

Table 1 presents the physicochemical properties of the prepared adsorbents. The residual moisture content of guinea corn husk $(96.80 \pm 0.56)$ is above that of maize cobs $(92.40 \pm 1.25)$. The quality of guinea corn husk in terms of ash (12.90 \pm 0.35$)$ is also above $7.3 \pm 0.4$ as well. Residual moisture of $1.04 \pm 0.15$ and $6.00 \pm 0.12$ was reported by Umar et al. ${ }^{[30]}$ for white grubs.

The guinea corn husk also gave a higher $\mathrm{pH}(6.3 \pm 0.17)$,

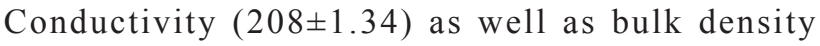

(12.27 \pm 0.61$)$. By the physicochemical parameters of the adsorbents, the maize cobs, being lighter than guinea corn husk and having the least moisture $(92.40 \pm 1.25)$, could withstand long storage than guinea corn husk without spoilage. This is probably why the ash content of $7.3 \pm 0.41$ was recorded against $12.90 \pm 0.35$ for guinea corn husk.

Accordingly, the high $\mathrm{pH}$ value $(6.3 \pm 0.17)$ recorded for guinea corn husk ensures that the guinea corn husk adsorbs the acid to a slower extent than maize cobs, which on the other hand, is more acidic (with a $\mathrm{pH}$ of 5.1 \pm 0.45 ). the bulk density for guinea corn husk $(12.27 \pm 0.61)$ overshadows that of maize cobs $(10.13 \pm 0.12)$ and that practically, entails that guinea corn husk is heavier than maize cobs, being denser.

Table 2 displays the values for adsorption equilibrium (Qe) at $660 \mathrm{~nm}$. Variable adsorbent dosage $(1 \mathrm{~g}, 2 \mathrm{~g}$ and $3 \mathrm{~g}$ ) of each molar ratio was used to test its efficiency for dye waste water decolourization under same condition. Their initial and final absorbance was used to estimate the Qe values. It is clear that the highest equilibrium for adsorption was reached at 1:1 with Qe value of 28.55, this is supported by the percentage yield calculated for the adsorbents at variable dosage (Table 4) which shows the best clearity at 1:1 dosage. The values for Qe were expressed by taking the average of 6 absorbance values of 2.189 , $1.404,1.631,0.834,0.486$ and 0.000 for $100,80,60,40$ 20 and $0 \mathrm{~g} / \mathrm{cm} 3$ as the Co (initial values) in a volume (v) of $50 \mathrm{~cm}^{3}$ and weight (w) of 1,2 , and $3 \mathrm{~g}$ as reported by ${ }^{[18]}$.

Table 3 displays the XRF results of the major oxides/ elements in the variable activated carbon fractions $(1: 1$, $1: 3$ and $3: 1$ ) in terms of the percentage available oxides in each. It is clear that the oxides present in the samples are the same although, their concentrations are different. This is attributed to the variation in the molar ratios of the guinea corn and maize husks which make up the samples. Similarly, the dominant oxide in each prepared carbon is $\mathrm{SiO}_{2}$ with percentage composition of $83.951,87.530$ and 75.417 in 1:1, 1:3 and 3:1 respectively. Accordingly, traces of oxides within the prepared ashes show similar oxide compositions as 8.2479 and 6.200 for $1: 1$ and 1:3 respectively except for sample $\mathrm{C}$ (with guinea corn husk to maize cobs ratio of $3: 1$ ) where the trace elements double the compositions of the first two (18.489). It is obvious that the amount of maize cobs overshadows that of guinea corn husk in the sample C. the results in Table 1 entails that the burn ability of guinea corn husk is better than that of maize cobs, due to size difference, moisture content and texture. Odewumi and coresearchers ${ }^{[33]}$ reported close values for porphyritic granite, medium grained granite, granite mneiss, early gneiss and average granite rocks with a dominance of $\mathrm{SiO}_{2}$. 
All the results show a moderate composition of $\mathrm{Al}_{2} \mathrm{O}_{3}$ and $\mathrm{Fe}_{2} \mathrm{O}_{3}$ as the dominant oxides in each, next to $\mathrm{SiO}_{2}$. Zhang and co-workers ${ }^{[34]}$ reported that similar precursor materials show similar but not exact oxide values. This is verified by the oxide compositions shown in the Table 1.

Percentage yield of adsorbents recovered in the dye waste water is presented in Table 4 after filteration of the fractions from the dye waste water, the recovered weights of the adsorbents is expressed in the variable ratios. The best yield (15.98, 10.65 and 9.79\%) were observed in 1:1 adsorbent dosage using $3 \mathrm{~g}, 2 \mathrm{~g}$ and $1 \mathrm{~g}$ dosage respectively, followed by $1: 3$ with ( $16.77,9.75$ and $7.32 \%$ ) moderate recovery while $3: 1$ adsorbent showed percentage recovery of $13.64,6.67$ and $5.40 \%$ for $3 \mathrm{~g}, 1 \mathrm{~g}$ and $2 \mathrm{~g}$ adsorbent dosage respectively. This corresponds to the findings of ${ }^{[18]}$, that the adsorbent dosage plays a key role along with contact time and temperature.

\section{Conclusion}

The findings in this research verify the claims of Mahmoodi et al. ${ }^{[18]}$ and Aziz et al. ${ }^{[20]}$ that adsorbents prepared from cellulose materials can effectively decolourize dye waste water. Furthermore, the dosage of adsorbents has a positive effect in decolourizing wate water. Further work will involve kinetic studies, full characterization and adsorption isotherms.

\section{References}

[1] Bansode, R. R., Lorso, J. N., Marshal, W. E., Rao, R. M. and Portier, J. (2002). Adsorption of metal ions by pecan shell granular activated carbon, Bioresource Technol.,89:p 115 - 119.

[2] Garg, V., Amita, M., Kumar R., Gupta, R (2004). Basic dye (methylene blue) removal from simulated waste water by adsorption using Indian rosewood sawdust. Dye and Pigment. 63(1): p243-250.

[3] Malik, P.K(2004) "Dye removal from wastewater using activated carbon developed from sawdust: adsorption equilibrium and kinetics, 'Journal of Hazardous Materials., Volume 113, Issues 1-3, 10,p 81-88

[4] JyotsnaGoel, Krishna Kadirvelu ChitraRajagopal, Vinod Kumar Garg,( 2005)"Removal of lead(II) by adsorption using treatedgranular activated carbon: Batch and column studies",Journal of Hazardous Materials., Volume 125, Issues 1-3, 17, p211-220

[5] Bansal, R. P. and Goyal, M. (2005). Activated Carbon Adsorption, CRC Press, Taylor \& Francis Group, 6000 Broken Sound Parkway N.W, Suite 300 Boca Raton, FL, USA.

[6] Crini G, badot, PM (2008) Progres in Polymer Sci- ence 33399

[7] Tadda, M.A. Ahsan, A, Shitu. A, ElSergany. M, Arunkumar, T. Bipin. J. Abdur Razzaque M. Nik Daud. N (2017). A Review on Activated Carbon: Process, Application and Prospects. Journal of Advanced Civil Engineering Practice and Research. 2(1):7-13,

[8] Labanda J, sabete, J Liorens, J (2009) journal of membrane science 340234

[9] Lenzy GG, Evangelista, RF, Duarte, ER, Colpini, LSM, Fornari AC, Neto RM, Jorge, LMM, and Santos OAA (2016) desalination and water treatment 57(30) 14132

[10] Shi, B, Li B Wang D Feng H and Tang H (2007) journal of hazardous materials 143567

[11] Akbari A, Remigy JC, and Aptel P (2002) Chemical Engineeering Processs 41601

[12] Pia AB, Roca, JAM, Miranda MIA, Clar AI, and Clar MII (2003) Desalination 15773

[13] Han R, Zhang J, Han P Wang y, Zhao Z and tang M (2009) Chemical engineering Journal 145496

[14] Shen, Y fan, CC, wei YZ, Du J, Zhu, HB and Zhao Y (2012) Dalton Trans 4510909.

[15] Lazim, ZM, Mzuin E, hadibarata T and Yusop Z (2015) Journal of Teknogi 74(11) 129

[16] Mittal, A, Jain, R, Mittal J, Varshey S and Sikarwar S (2010) International Journal of Environmental Pollution 43308

[17] Ngah, WS, Teong LC, and hanafiah, MAKM (2011) carbohydrate Polymers 831446

[18] Mahmoodi NM, Arami M and Gharanjig K (2013) Journal Of Environmental And Chemical Engineering 1406

[19] Kiakhani, MS, Arami, M and gharanjig, K (2013) Journal Of Environmental and Chemical Engineering 1406

[20] Aziz, H.A., Aliaz, S., Adian, M.N., faridah, Assari, A.H. and Zahari, M.S. (2007) Color removal from landfill leachate by coagulation and Flocculation processes. Bioresource Technology. 98 218-220

[21] Buah. W. MacCarthy, J. Ndur, S.(2016). Conversion of Corn Cobs Waste into Activated Carbons for Adsorption of Heavy Metals from Minerals Processing Wastewater. International Journal of Environmental Protection and Policy. 2330-7536

[22] Galvan-Ruiz, M., Hernandez, J., Banos, L., Noriega-Mntes, J. and Rodriguez-Garcia, M.E (2019). Chaarcterization of Calcium Carbonate, Calcium Oxide and Calcium Hydroxide as Starting Point to the Improvement of Lime for Their Use in Construction. American Society of Civil Engineers (ASCE) 1-20 available online at https://www.researchgate.net/publication/232815496 
[23] Kaghazchi T, Madadi M, Yeganeh, M. Soleimani,(2006) in proc. Of CHISA (Ed: Jan Novosad), Czech Society Chemical Engineers, Prague, Czech Republic,

[24] Odebunmi, E., Okeola, F (2001). Preparation and characterization of activatd carbon from waste material. Journal chemical society of Nigeria 26(2): 49155.

[25] Itodo, U.A (2010); Comparative Studies on the preparation, Adsorption and Evaluation of Activated carbon from selected Animals and agricultural wastes. a Ph.D thesis UDUS

[26] Omomnhenle, S., Ofomaja, A., Okiemen, F (2006) sorption of methylene blue by unmodified and modified citric acid saw dust. Journal chemical society of Nigeria. 390 (1 and 2): p161-164.

[27] Zahangir, A., suleyman A. and Noraini, K (2008) production of Activated carbon from oil palm empty fruit Bunch for Zn Removal. Bul. Conference proceedings 12th int'l water Tech conf. IWTC12 Egypt. P373-383.

[28] Gimba, C., Ocholi, O., Nok, A (2004). Preparation of activated carbon from agricultural $\backslash$ coastes ii. cyanide binding with activated carbon matrix from groundnut shell. nig journal of scientific research. 4 (2); p106110.

[29] Rahman, A., Saad, B., Shaidan, S. and Rizal, S. (2002). Adsorption characteristics of malachite Green on ctivated Carbon Dervied from Rice Husks pro- duced by Chemical Thermal process. Bioresearches Technology, 90(14): p1578-1583

[30] Umar, K. J., Alhassan, M. Ahmad, T. I., Zauro, S. A., Sani, N. A., Lawal, A. M. \& Hassan, L. G.(2012). The Proximate, Mineral And Fatty Acids Profile Of White Grubs (Scarabidae) African Journal of Natural Sciences 2012, 15, 7 - 11

[31] Yoshiyuki, S.,. Yutaka, K. (2005) paralysis of plant, animal and Human waste; physical chemical charctristics of the pyrolytic product. Bioresoruce Technology 90(3); p241-247

[32] Alhassan, M., Faruq, U.Z. and Galadima, A. (2019). Mixed-Metal Oxide Catalyst for Liquid Phase Benzene Alkylation. Earthline Journal of Chemical SciencesISSN (Online): 2581-9003 Volume 2, Number 2, 2019, Pages 217-234 https://doi.org/10.34198/ ejcs.2219.217234

[33] Odewumi, S.C., Adekeye, J.I.D. and Ojo, O.J. (2012) Petrogenesis and Geotectonic settings of the Granitic rocks of Idefin-Osi-Eruku Area, South western Nigeria Using trace Elements and Rare Earth Element Geochemistry. African jurnal of Natural Sciences 15, 39-51

[34] Zhang, B. , Ji, Y., Wang, Z., Liu, Y., Sun, H., Yang, W. and $\mathrm{Wu}, \mathrm{P}$. (2012) Liquid-phase alkylation of benzene with ethylene over postsynthesized MCM-56 analogues, Applied Catalysis A:General 443-444; 103-110. https://doi.org/10.1016/j.apcata.2012.07.028. 